\section{Creación de la memoria iconográfica de una cooperativa de bordadoras indígenas, un ejercicio ético para el diseñador}

\author{
Ruth Verónica Martínez Loera ${ }^{(*)}$
}

\begin{abstract}
Resumen: En el municipio de Chilón, Chiapas está la cooperativa “jLuchiyej Nichimietic”, un espacio donde se comercializan los bordados de doscientas mujeres indígenas tseltales. Ellas han creado una iconografía relacionadas con la flora y fauna de la región y también con algunas expresiones de su cosmovisión. Para conservar el legado visual se generó un proyecto que documentó el sentido simbólico de los dibujos a través de técnicas creativas generadas desde el diseño. Es importante mencionar que dicha actividad tiene un trasfondo ético que reta a conservar saberes y a no utilizar el material en propósitos distintos a los de la cooperativa.
\end{abstract}

Palabras clave: bordadoras indígenas - memoria iconográfica - compromiso ético - responsabilidad social - ética profesional.

[Resúmenes en inglés y portugués en la página 57]

${ }^{(*)}$ Egresada de la licenciatura y maestría en diseño gráfico de la Faculta del Hábitat. Obtuvo el título de Doctora en Estudios Científico Sociales por el Instituto Tecnológico y de Estudios Superiores de Occidente. Ha colaborado con diversos proyectos editoriales y de estudios iconográficos para la comunidad tseltal de Chilón, Chiapas desde el año 2002. Profesor investigador de tiempo completo, con perfil PRODEP en la Facultad del Hábitat, de la Universidad Autónoma de San Luis Potosí. Su trabajo gira en torno a la epistemología del diseño, la iconografía indígena, los procesos y los estudios culturales. veronica.loera@uaslp.mx

\title{
Introducción
}

A lo largo del tiempo la ética ha sido descrita como la distinción entre lo permitido y lo prohibido. Un lineamiento que rige el actuar de los individuos en un entorno social a través de actitudes y hábitos. Para los pueblos indígenas a través de la armonía, justicia y verdad entablan una serie de principios que rigen su organización y dinámica comunitaria, pero sobre todo su relación con el entorno que los rodea. La comprensión del mundo se 
concibe en conexión de lo humano con la naturaleza un sentido de diversidad que genera "modos muy distintos de ser, pensar y sentir, de concebir el tiempo, la relación entre seres humanos y entre humanos y no humanos, de mirar el pasado y el futuro, de organizar colectivamente la vida, la producción de bienes y servicios y el ocio" (Meza, 2017, p. 147). La cooperativa "jLuchiyej Nichimetic" es un espacio concebido como lugar de encuentro e intercambio de saberes que giran en torno al bordado. Una actividad que combina las labores domésticas con las del cuidado de la tierra y también con la espiritualidad que las mujeres han sabido registrar a partir de dibujos y colores. Más de cuarenta años de trabajo colectivo han generado un banco de información visual por medio de la cual han compilado distintas historias y momentos de las comunidades.

El legado iconográfico es amplio y en ocasiones poco conocido por las mismas bordadoras. Eso generó el interés por crear un proceso de recuperación de la memoria y de la historia de la cooperativa a través de imágenes. Sin embargo, saber sistematizar la experiencia, clasificar las figuras e interpretar las composiciones no ha resultado una tarea sencilla, no bastó con la intuición fue necesario el acompañamiento y asesoría del diseñador. El curso "trazos de la historia" se planteó la discusión y el análisis desde la propia cosmovisión y pensamiento indígena y se utilizó su pensamiento creativo para adentrarse a través de la memoria a la habilidad técnica de tal modo que impactará en la esencia de ser una cooperativa, así se estableció la dinámica de mirar y leer la realidad a partir de experiencias del mundo social.

El trabajo llevado a cabo bajo las normas éticas tseltales enfrenta un reto para aquellos que han producido conocimiento sobre el sistema de organización comunitaria, productos artesanales, cosmovisión y cultura del pueblo tseltal a través de escritos, fotografías, dibujos o videos. Se piensa que se vende la información, que quien publica obtienen una ganancia económica o que comenzará un negocio. Estas inquietudes retan al diseñador a actuar bajo la idea de actuar con mesura y conciencia de los límites que hay entre favorecer el conocimiento sobre una comunidad y emplear el material en su beneficio creativo (Giusti, 2018).

\section{La cooperativa de las bordadoras de flores.}

México es una nación multicultural, multilingüe y megadiversa. Uno de los estados que coincide con todas esas características es Chiapas y particularmente sus comunidades indígenas Choles, Amuzgos, Jacaltecos, Mochos, Mames, Chujes, Lacandones, Acatecos, Zoques, Tojolabales y Tseltales. Estos últimos están distribuidos en la zona de los Altos en alrededor de trece municipios y por tanto, donde se encuentran por lo menos cinco variantes idiomáticas, veinte estilos de indumentaria y cinco formas de organización comunitaria (Martínez, 2011).

En el caso concreto del municipio de Chilón todavía se identifican tres variables del tseltal, así como cuatro distintos tipos de indumentaria en la que destaca el bordado de las mujeres de la cabecera municipal. Es posible que tantas diferencias se deban a que, durante por lo menos los últimos cuatrocientos años las comunidades indígenas fueron sometidos a vivir bajo el sistema de encomienda y reducción o bien, formaron parte de los inventarios 
de las fincas dedicadas a la intromisión de monocultivos, extracción de maderas finas o a la crianza de ganadería (París, 2007).

La dificultad social y económica dio pie a la creación de proyectos que vieron en las actividades cotidianas y en la indumentaria una posibilidad de crecimiento. Durante los años sesenta el plan pastoral de Samuel Ruiz García y el trabajo de las religiosas del Divino Pastor fomentaron el aprovechamiento de frutas, plantas medicinales y también del bordado como alternativas para subsanar las condiciones de pobreza y precariedad (Womack, 1998; Almeyra, 2009). La idea no era formar negocios sino espacios de intercambio y participación por medio de los cuales se obtuvieran abarrotes, medicamentos o materias primas para actividades agrarias. Por otra parte, también se visualizaba la necesidad de fomentar espacios para las mujeres.

El establecimiento en el pueblo de Chilón, la constante visita a comunidades y la identificación de situaciones de vida hicieron posible que se viera en el bordado una alternativa para incentivar la economía doméstica. Además, que se buscaran alternativas que se ajustaran a la dinámica de vida indígena. El cooperativismo como modelo de colaboración y norma ética propició el crecimiento y bienestar de las comunidades a partir la solidaridad, esfuerzo propio y ayuda mutua, valores que para los tseltales estaban asociados a la armonía y justicia (Maldonado, Alvarado y Contreras, 2015; Maurer, 2009). Además, la organización requirió asignar responsabilidades a cada integrante ya fuese como presidenta, secretaria, tesorera o socia, roles asociados al sistema de cargos. Una forma de organización política y religiosa que permite a una persona desempeñar por un tiempo determinado una actividad que beneficie el desarrollo de la comunidad (Maurer, 2007). El esquema de la cooperativa quedó configurado en cuatro espacios, asamblea general, consejos, artesanía y bordado -ver Fig. 1-.

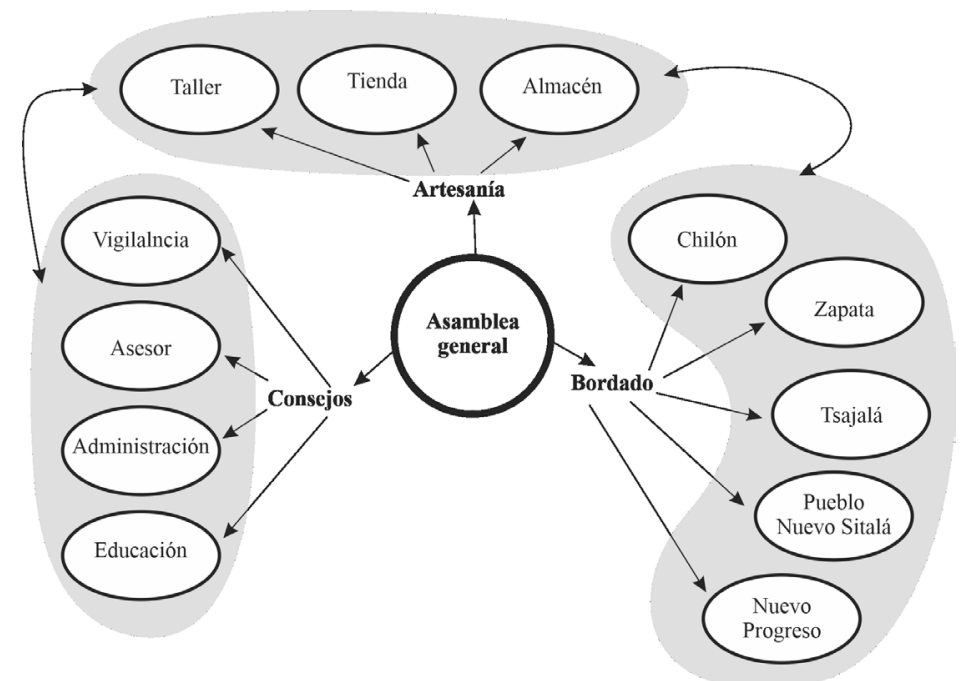

Figura 1. Organización de la cooperativa. Fuente: elaboración propia. 
La cooperativa no ha sido consideradamente como un negocio, sino como un sistema de alianzas organizacionales y administrativas que dan cuenta del crecimiento económico y social de las socias, sus familias y comunidades (Ishikawa y Strandberg, 2009). Para ello han establecido acuerdos que determinan el estímulo económico por cada pieza bordada. Eso ha generado una calendarización que considera tiempo de entrega, cantidad de piezas, calidad de la imagen, combinación de colores. Parámetros explicados desde el sistema empresarial como competitividad y beneficio o bien desde el punto de vista social, como la construcción de relaciones y posiciones que dan sentido al campo del bordado (Vara, 1985; Bourdieu, 1997). Esto se puede explicar a partir de la norma de comprar insumos en la tienda de la cooperativa con el fin de mantener la calidad de hilos, colores, telas. No se aceptan bordados con materiales provenientes de otro lugar porque eso rompe con los estándares de calidad asumida a partir de la experiencia de comercialización de sus productos en el mercado artesanal. Como pudo verse, el establecimiento de costos y ganancias es relevante si se toma en cuenta que son aspectos pocas veces considerados en la comercialización y la ganancia económica del artesano (Turok, s/f; Mejía, 2004).

La socia hace su bordado, lo entrega en la fecha acordada, se le paga y su lienzo se lleva al taller en donde es transformado en artesanía. Esta actividad es la que ha recibido capacitación de corte y confección por parte de diseñadores que también han aprovechado el espacio para proponer modelos de bolsas, morrales, portacelulares, blusas, vestidos, carteras, servilleteros y recientemente zapatos. Productos que propiciaron la participación de asociaciones civiles bajo los lineamientos de comercio justo y la economía solidaria, cuya visión sirvió también para la mejora de materias primas de tal modo que con ello se expandiera la venta de productos a nivel nacional e internacional con lo cual se logró la ampliación del mercado (Turok, s/f). Otra participación del diseño en la cooperativa fue la creación de la marca. En sus inicios, solamente se identificaron como "nichim" o flor en tseltal un nombre empleado para el registro ante hacienda. Pero, en el año 2004 por reformas fiscales y conveniencia administrativa se cambió a "jLuchiyej Nichimetic". El nombre para las mujeres representó su la conexión con elementos simbólicos de tipo cultural y religioso, porque la flor está relacionada con la vida y la naturaleza. El trabajo colaborativo es significativo pues, las mujeres nunca bordan solas -ver Fig. 2-. Como parte de la cosmovisión de los pueblos indígenas se destaca "ser-comunidad, vivir-en-comunidad, trabajar-en-comunidad: se trata de una cosmovivencia con un carácter complementario, solidario, cooperativo, de ayuda mutua [...] hay una fuerte vivencia de comunalidad y no de individualidad" (Meza, 2017, p. 148.149).

Figura 2. Sentido de comunidad representado en la marca.

Fuente: elaboración propia a partir del diálogo con la diseñadora Yanen Ali Modad.

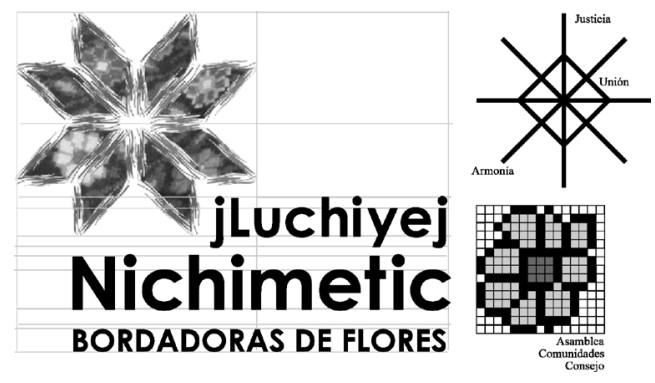


Con el diseño de marca se implementaron algunos medios gráficos, catálogos, página web, tarjetas de presentación y facturas. El proceso comenzó en asamblea general para informar la actividad a todas las socias. Diálogo con los consejos asesor y de vigilancia con alumnos de servicio social provenientes de algunos de los campus de la Universidad Iberoamericana o bien del ITESO, instituciones que pertenecen al sistema universitario jesuita, en el que se fomenta el sentido comunitario y de responsabilidad social. En varios de los medios propuesto se utilizaron figuras de los bordados, un ejercicio que generó el aprendizaje de la dinámica social, ideológica y comercial que visualiza la transformación, interacción y sentido al proyecto a través de la participación conjunta de diseñadores y socias fortaleciendo en gran medida el sentido integral del proyecto.

La sensibilidad a las necesidades dio pie al liderazgo de servicio como una actitud que determina el proceso de reconocimiento y posibilita el fortalecimiento social de un grupo humano (Afkhami, Eisenberg. y Vaziri, 2005; Navarro. 2005). El trabajo colaborativo a su vez fomentó una economía emergente, democrática y de gestión que elevó la calidad de vida y las oportunidades de desarrollo desde el punto de vista de la solidaridad (Maldonado, Alvarado y Contreras 2015).

\section{La memoria de la cooperativa contada en imágenes}

Las mujeres suelen contar con frecuencia que la convivencia con montañas, ríos, cafetales y potreros les proporciona plantas y animales como alimento dador de vida. En la milpa encuentra flores e insectos. A la orilla de ríos observa mariposas y peces. En la montaña percibe el alma de los animales sagrados y las voces de los antepasados. También saben que el cielo es negro porque les regalará la lluvia o rojo cuando indica el momento oportuno para sembrar o cosechar (Martínez, 2011). Todas estas conexiones con la tierra engloban visiones místicas, religiosas, artísticas, filosóficas por medio de las cuales se interpreta el mundo (Meza, 2017).

Las historias contadas están estrechamente relacionadas con nacimiento, crecimiento y muerte. Todo se aprende, da vida y se comparte. Por eso, la habilidad de conocer el entorno refleja todo lo que sus antepasados les heredaron y que tienen que mantener para futuras generaciones (Espinosa de los Monteros, 2016). Contar lo que se conoce es parte de la historia oral o bien, de pues "la palabra toca al corazón" (Paoli, 2003, p. 85). Aunado a ello, está la imagen, pues esta "representa la sabiduría" (Martínez, 2011). Entre la palabra y la imagen hay dos soportes que sostienen la admiración por la vida (González, 2004). La construcción de la memoria a través de la palabra y la imagen es una estrategia que genera un sistema de aprendizaje (Kaplún, 1998). Palabra e imagen también se convierten en un juego, donde la creatividad favorece el intercambio de información y la generación de saberes locales (Araya, 1996).

La memoria es un proceso dinámico, recordar es la reconstrucción del pasado (Rains, 2002). La palabra conduce a mundos desconocidos e inéditos (Meza, 2017). Escribir lo que se escucha permite aprehender una realidad que hasta el momento se nos presentaba en forma incompleta. Dibujar preserva las características de la experiencia visual que se guarda sobre 
objetos, lugares, animales o personas (López, 2011). Sin saberlo, las mujeres de la cooperativa trabajaron una estrategia que les sirvió para identificar la procedencia y autoría de las imágenes de los bordados. Determinaron roles a partir de sus habilidades para hablar, escuchar, escribir, dibujar o bordar. Como resultado obtuvieron información sobre la técnica y la procedencia de figuras, pero quedó débil el aspecto simbólico de la iconografía.

El curso "Trazos de la historia" se creó para que las socias con más de treinta años de participación en la cooperativa platicaran su experiencia a quienes llevaban poco tiempo de formar parte del proyecto. Además, se buscó recuperar la expresión de la técnica del bordado de punto de cruz y la construcción de nuevas imágenes Por tal motivo se entrelazó diálogo, memoria, acuerdo y celebración en tres momentos relacionados con saberes, comunidad y figuras, aspectos por medio de los cuales se generó análisis de contexto, crítica dialéctica y praxis sustentados en la educación y comunicación popular (Freire, 2002), con la intención de "que los destinatarios tomen conciencia de su realidad» [...] «para suscitar una reflexión» $[. .$.$] «para generar una discusión» [...] como alimentadores de un proceso$ educativo transformador" (Kaplún, 1998, p. 11).

La iconografía como recurso pedagógico e instrumento de análisis sirvió para adentrarse a la comprensión de todos aquellos factores que influyen en la configuración de una imagen, pues en los elementos formales y compositivos se recupera la experiencia práctica (Panofsky, 1996), el sentido de producción (Bourdieu, 2000), la simbolización personal y colectiva (Belting, 2007) y de alguna manera la expresión estética (Lizarazo, 2006). La propuesta de actividades y el material didáctico retomaron a la imagen como recurso así se propició la confianza y entusiasmo características fundamentales en un proyecto participativo (Araya, 1996) -ver Fig. 3-.

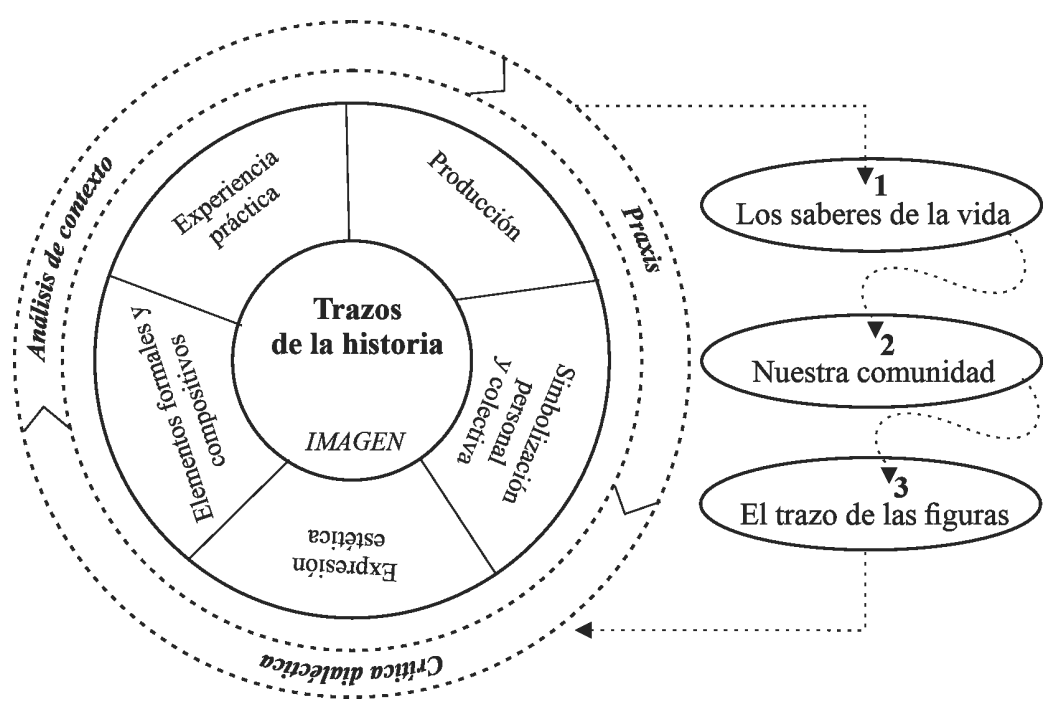

Figura 3. Esquema teórico metodológico del curso para las mujeres. Fuente: elaboración propia. 
El primer momento del curso "los saberes de la vida" giró en torno al recuerdo de abuelas, madres o hermanas mayores y su experiencia con el bordado a través del diálogo. Una estrategia de aprendizaje donde la persona interpreta el mundo vivido como punto de partida para retomar la historia (Russo, 2002). También se utilizó la fotografía por ser un procedimiento que tiene un nivel de iconicidad describe, insinúa, crea, transmite deseos, expresa sentimientos y pensamientos (CNCA, 2015).

La observación de saberes hizo posible adentrarse al registro de la vida cotidiana que hacen las mujeres. Sobre todo, evidenció el sentido simbólico la distribución de imágenes sobre el lienzo, pues para las bordadoras el lienzo representa la tierra y la cruz la semilla de maíz un alimento considerado sagrado para la vida comunitaria (Morante, 2000; Martínez, 2011) -ver Fig. 4-.
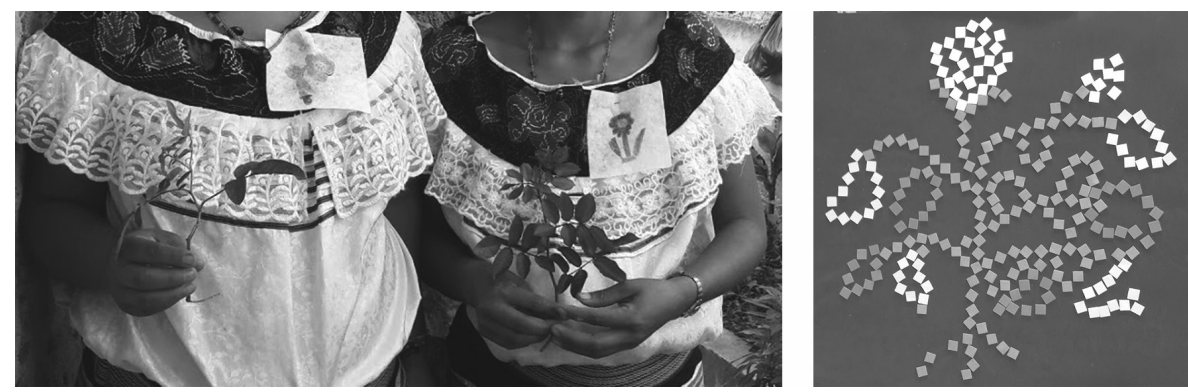

Figura 4. Selección de plantas de la milpa simulando una figura para el bordado.

Fuente: fotografías tomadas por las mujeres participantes en el curso.

El segundo momento "nuestra comunidad" se centró en la revisión bordados con ello se recuperaron expresiones gráficas a partir de la cosmovisión maya-tseltal. Se centró en la interpretación de símbolos a partir de una estructura de significación y comunicación (Bauman, 2002). Tomando en cuenta que un signo difícilmente tiene sentido por sí mismo si se separa del resto de elementos que lo conforman (Douglas, 1978). Además, se buscó la red de relaciones sociales que dentro del entramado cultural evidencian la identidad (Bauman, 2002).

El ejercicio sirvió para recuperar la expresión de la cruz, la cual representa los cuatro puntos cardinales, marca el ciclo de la vida a partir del crecimiento del maíz y simboliza la fiesta y oración actividades que mueven al universo y dan sentido a la comunidad (Martínez, 2011). El rombo simboliza la caminata para entrar y salir del cielo, la tierra y el inframundo, un recorrido que señala el crecimiento del maíz como de flores, plantas, o bien, se considera el corazón dador de vida y armonía de todo lo germinado en la naturaleza (Morales, 2006; Florescano, 2000). Por otra parte, se mencionó que las flores incorporan a la persona tanto en la familia como en la comunidad. Es así, como rombos, flores y colores, todo se une para representar el orden del cosmos y el orden social (Paoli, 2003) -ver Fig. 5-. 

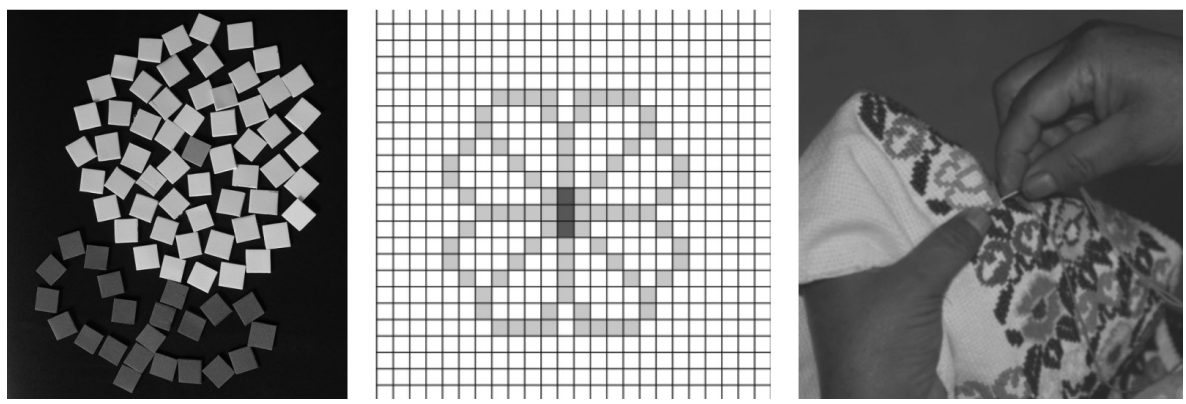

Figura 5. Recuperación de imágenes simbólicas y su proceso de creación. Elaboración propia.

El último momento "el trazo de las figuras" se centró en el aspecto compositivo y los saberes técnicos. Ya que la organización visual permite sean apreciados todos los elementos que conforma una composición (Ledesma, 2003). Además, la pauta creativa de la proporción, estilo, dibujo y color son elementos esenciales de un trabajo artesanal (Turok, 1988). Una estrategia empleada fue el boceto como recurso que buscó la concreción, prueba y experimentación de ideas antes de llevarlas a la materialidad (Olivares y Vilahur, 2014). Se utilizaron hojas cuadriculadas para que, con punto, línea, plano se formaran parones visuales que sirvieran para la geometrización.

Los elementos empleados favorecieron la percepción de la repetición, con lo cual observaron ritmo y armonía formados por puntos geométricos que, de acuerdo con las yes de la naturaleza, forman diferentes figuras, variaciones de tamaño, movimiento, tensión y dirección (Kandinsky, 2003). Así aparecen líneas que ascienden y descienden dentro del campo visual, o bien, marcan pautas de repetición, simetría y contraste, reforzado con los matices de color.

Para las bordadoras la distribución de imágenes no empela un trazo previo sobre el lienzo, se distribuyen las figuras y los colores aparentemente de manera espontánea. Sin embargo, los elementos y sus proporciones son semejantes a los principios compositivos empleados en la elaboración de glifos (Kettunen y Kelmke, 2004; Coe, 1986; Knórosov, 1982; Hasselkus, 1998).

El desplazamiento de figuras representa el baile en la fiesta patronal; la oración a la tierra y también los acuerdos comunitarios (Martínez, 2011). Aspectos que dentro de la cosmovisión tseltal están relacionados con la armonía y la dignidad humana (Maurer, 1984) -ver Fig. 6-. 

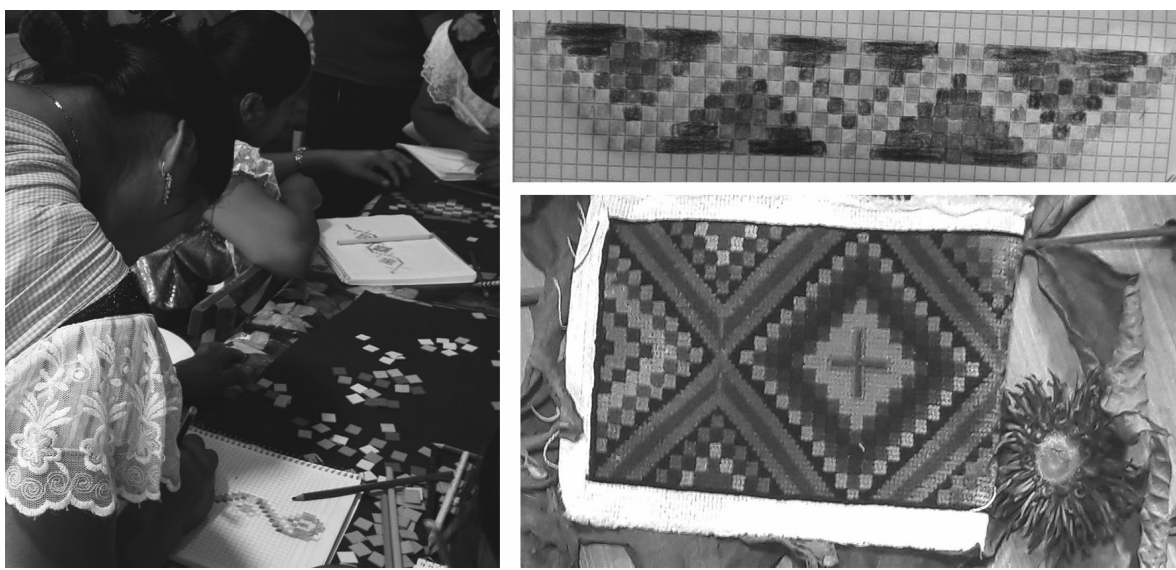

Figura 6. Representación de una flor a partir de cuadros que simulan las puntadas del bordado; trazos básicos y bordado. Fuente: elaboración propia.

El ejercicio creativo dio pie a que se profundizara en el sentido que tiene la imagen para el pueblo tseltal. La dinámica del juego se empleó con la intención de que las mujeres participaran de manera individual o en equipo y que se sintieran motivadas a compartir su experiencia (Araya, 1996), de este modo se logró que cada momento aportara datos con los cuales se apreció la importancia del bordado como parte de la vida comunitaria.

\section{La gestión social del diseño gráfico.}

La participación del diseñador gráfico dentro del proceso de recuperación iconográfica ha servido para que las mujeres vean en las imágenes un legado. También para que se busquen nuevas formas de documentar y conservar los saberes, Y sobre todo para crear confianza en que los procesos creativos de la comunidad aun cuando reciban asesoría externa, no cambiarán de dueño. Si consideramos esto como un eje ético dentro de la profesión, pues en los últimos años la intervención en el trabajo artesanal se ha visto amenazado por plagios, apropiación de saberes o bien, creación de empresas que hacen uso de expresiones culturales donde el menos beneficiado es el indígena.

El diseño gráfico está al servicio de cualquier grupo social a partir del desarrollo de ideas o de aspectos sensibles que dan sentido a la conservación de un ámbito cultural como el indígena. Así, "esta disciplina mostrará que no está sometida a los dictados del consumo y el mercado" (Ledesma, 2003, p. 10). Es importante que se reflexione que la intervención del diseñador recupera de manera constante manifestaciones de la cultura. Es decir, "el diseñador actúa sobre la cultura trascendiendo los límites de su propio producto, convirtiéndose en un 'operador cultural" (Soliz, 2012. p. 14). 
Entonces, se puede decir, que el compromiso ético del diseñador radica en brindar herramientas que hagan que la cultura se fortalezca, de tal manera que poco a poco se perciba en la esfera pública la responsabilidad con la que lleva a cabo procesos creativos (Pelta, 2010), sobre todo, en el que un grupo social reconoce la importancia que tienen conservar su memoria y con ello, el patrimonio tangible e intangible que le ha dado identidad.

Adentrase al ámbito de la cultura indígena desde los estudios culturales favorecen el establecimiento de una alianza entre quien recupera datos con el que los proporciona. Es decir, involucrar a la comunidad en todo el proceso generará la confianza de que, en su momento, la información recabada será parte de su legado. Adentrarse a la comprensión de la producción, creación y difusión de significados carece de sentido si se centra únicamente en la visión de quien investiga o de quien vive en el espacio social. La oportunidad de llevar a cabo acciones colaborativas favorecerá la compresión de prácticas y actividades cotidianas que dan sentido a un grupo social (Urrego, Coral, Aristizabal, Bello y Bastidas, 2017; Agar, 2004; Meza, 2017).

El sentido de reciprocidad y compromiso de quien se ha interesado en los fenómenos culturales del ámbito artesanal servirá para que constantemente se considere que, desde el punto de vista del mundo indígena, los acuerdos, la palabra son ejes que establecen una relación que va más allá de lo profesional, puede decirse que es una lección de ética vista como una práctica de vida (González, 2007). De esta manera la gestión social tiene como reto recuperar los valores de armonía, justicia y verdad entablan una serie de principios que rigen su organización y dinámica comunitaria con la cual los pueblos indígenas conciben la dinámica social (Meza, 2017).

La puesta en práctica del trabajo de diseño que mana desde la universidad o el profesionista tiene que considera el compromiso social adquirido con la comunidad. No como discurso emotivo, sino, como respuestas realista, eficaz y comprometida desde las dimensiones teórica, técnica y ética (Agejas, Parada, Oliver, 2007: Cobo, 2011). En este sentido la ética de la profesión propone principios específicos donde los conocimientos y destrezas han de utilizarse para ir más allá de una ocupación que permite obtener ingresos y estatus social de tal manera que con ello contribuya a elevar la calidad de vida de un grupo social (Ibarra, 2007; Bolívar, 2005). La información recabada en cualquier tipo de intervención desde el diseño tiene la posibilidad de gestar nuevas propuestas creativas. Algunas, con intención de regresar a la comunidad de origen, otras, posiblemente se adentrarán al ámbito de lo comercial. Cualquier que sea el camino, vale la pena que se considere el diálogo con la comunidad que conoció y de la cual obtuvo formas, objetos o conceptos que empleará en nuevos proyectos que demandan la transformación del proceso que dio origen. Esa manera de actuar genera poca credibilidad en el desarrollo de capacidades intelectuales que tiene el interés de mejorar las condiciones de un grupo social (Kaplún, 1988).

La modificación del sentido simbólico también tiene implicaciones en la lucha por el reconocimiento político, como el derecho ancestral de las comunidades indígenas sobre sus territorios, a la identidad cultural y a la supervivencia misma de la comunidad (Espinosa de los Monteros, 2016). Porque la vanalización de significados genera que las expresiones culturales sean consideradas meros rituales desdibujado el sentido de su historia colectiva, memoria ancestral o espacio social (Fernández y Hermansen, 2009). 
La petición de las comunidades indígenas a que sean respetados sus recursos creativos no pretende guardar su tradición como un elemento viejo, sino como algo que mantiene vivos los bienes patrimoniales de su propia cultura. Por eso es importante el sentido de memoria, identidad y el sentido de vida que tiene un valor simbólico que se transmite de una generación a otra (Arévalo, 2004). De ahí la importancia de conocer costumbres, conocimientos y sistemas de significados para que puedan ser protegidos desde su sentido material e inmaterial (Bonfil, 2004, p. 119).

\section{Conclusión}

Adentrarse a la configuración de una cooperativa de bordados tuvo la intención de configurar el espacio simbólico del pueblo tseltal con la intención de que sus saberes y habilidades mostraran la importancia que tiene la expresión visual. Desde la cual es posible configurar proyectos de formación cultural y de desarrollo social. Un reto para la construcción de conocimiento que impacte en la vida cotidiana de las comunidades que configuran el pueblo tseltal.

Todavía hay muchas cosas que hacer y apartar a las comunidades indígenas como la tseltal, sobre todo, porque los proyectos avanzan a ritmo lento. Sin embargo, son experiencias que se convierten en retos para el desarrollo de conocimiento, para la reflexión sobre la propia disciplina del diseño y también para la generación de investigaciones que combinan recursos metodológicos envueltos por pedagogías sociales, un aspecto que ha sido poco abordado dentro de los espacios de formación y sobre todo dentro del campo profesional. Vale la pena pensar, que las habilidades para la creación de estrategias comunicativas, tecnológicas o de persuasión suelen ser útiles para buscar el fortalecimiento de aquellas poblaciones que tienen en la imagen y la creatividad, la posibilidad de interpretar la realidad en la que viven.

También es importante ver, que la intervención del diseñador genera confianza, pues se sabe, que las acciones que propone están acompañadas de argumentos teóricos y metodológicos con un sentido solidario y de respeto. Es decir, que la participación busca el desarrollo social, antes que el personal.

\section{Lista de Referencias Bibliográficas}

Afkhami, Mahnaz, Eisenberg, A. y Vaziri, H. (2005). Liderazgo para la toma de decisiones. Manual de entrenamiento en liderazgo para mujeres. Marruecos: Asociación de Mujeres por el Aprendizaje de sus Derechos, El Desarrollo y La Paz (WLP).

Agar Corbinos, L. (2004). La ética de la investigación en ciencias sociales en el contexto de la globalización: de la investigación cuantitativa a la investigación cualitativa. Acta 
Bioética 10[1], p.p. 65- 68. Disponible en https://scielo.conicyt.cl/scielo.php?script=sci_ abstract\&pid=S1726-569X2004000100008\&lng=es\&nrm=iso

Agejas, J. A., Parada, J. L. y Oliver, I. (2007). La enseñanza de la ética profesional en los estudios universitarios. Revista Complutense de Educación 18[2], p.p. 67-84. Universidad Francisco de Vitoria. Madrid. Disponible en https://core.ac.uk/download/pdf/38820755. pdf

Almeyra, G. (2009, abril). Quince años del EZLN y la autonomía en Chiapas. OSAL, X[25]. Disponible en http://bibliotecavirtual.clacso.org.ar/ar/libros/osal/osal25/10alme.pdf

Araya, E. (1996). Juegos y técnicas de animación para la escuela básica. Santiago: Argé Comunicaciones.

Arévalo, J. M. (2004). La tradición, el patrimonio y la identidad. Revista de estudios extremeños, 60(3), 925-956. Disponible en https://d1wqtxts1xzle7.cloudfront.net/53493025/ LECTURA2E.pdf?1497384409=\&response-content-disposition=inline $\% 3 B+$ filename $\% 3$ DLa_tradicion_el_patrimonio_y_la_identida.pdf\&Expires $=1592181529 \&$ Signature $=$ FS2Ym7KWtrDTMoA9Rva3qzQ-PUd8OR73Baz L4s7NeJa8Nb-hERGOeJnzBWTr7ToRa9Y-6 1DL3m I RB8loxITjxSnMc24IFXLZcMnFvhj2Zap2KTagS6zwvn1Q4J8q6Zn7KmBPNf1c6S80IIOjMSs8B11n7QCAxzlDA1Dy1k8a4Yh13MafnHzypEwIBrPBAMbPiRi97ux1JRo6Ea4s2hBV-RrGnhqQ50aKTmhrBcbK62KNyxmBOzPsbW-CeFTU3 YvA$\sim$ fPTFGK3Asj3sCclmKT kTJXrrO4EGeEZ5HIK6rwSiQWw9 rmHb8RpB17NHnh2r wZ8WmHWpUtU4Rrr0A_\&Key-Pair-Id=APKAJLOHF5GGSLRBV4ZA

Bauman, Z. (2002). La cultura como praxis. Barcelona: Paidós.

Belting, H. (2007). Antropología de la imagen. Argentina: Katz Editores.

Bolívar, A. (2005, enero-marzo). El lugar de la ética profesional en la formación universitaria. Rmie, 10[24], pp. 93-123. Disponible en http://www.scielo.org.mx/pdf/rmie/ v10n24/1405-6666-rmie-10-24-93.pdf

Bonfil Batalla, G. (2004). Patrimonio cultural inmaterial: Pensar nuestra cultura. Disponible en http://observatoriocultural.udgvirtual.udg.mx/repositorio/bitstream/handle/123456789/120/Batalla-Pensar.pdf? sequence=1\&isAllowed $=y$

Bourdieu, P. (1997). Razones prácticas, sobre la teoría de la acción. México. Anagrama.

Bourdieu, P. (2000). Las estructuras sociales de la economía. Buenos Aires. Manantial.

CNCA. (2015). El potencial educativo de la fotografía. Santiago: CNCA (Consejo Nacional de la Cultura y las Artes).

Cobo Suero, J. M. (2001). Ética profesional en ciencias humanas y sociales. Madrid: Huerga y Fierro Editores.

Coe, M. E. (1986). Los Mayas. México: Editorial Diana.

Douglas, M. (1978). Símbolos naturales. Exploraciones en cosmología. Madrid: Alianza Editorial.

Espinosa de los Monteros Rodríguez, A. (2016). Bioética de los pueblos indígenas. Revista Bioderecho.es, 3, Centro de estudios es bioderecho, ética y salud. Universidad de Murcia. Disponible en https://digitum.um.es/digitum/bitstream/10201/50640/1/Bioetica\%20 de\%20los\%20pueblos\%20indigenas.pdf

Fernández Droguett, R. y Hermansen Ulibarri, P. (2009). Aproximaciones metodológicas para una sociología visual a partir del estudio de prácticas de memoria colectiva en el 
espacio público de la ciudad de Santiago de Chile. Espacio Abierto, 18(3),445-460. Disponible en: https://www.redalyc.org/articulo.oa?id=122/12211825003

Florescano, E. (2000, invierno). La visión del cosmos en los indígenas actuales. Desacatos, 005. 15-29. Disponible en http://www.ciesas.edu.mx/desacatos/05\%20Indexado/Saberes_1.pdf

Freire, P. (2002). La pedagogía del oprimido. Buenos Aires: Siglo XXI.

Giusti M. (2018, agosto). Curso "introducción a la ética". Clase 1: ¿A qué llamamos Ética? El talón de Aquiles. Portal de recursos para la enseñanza de la filosofía. Pontificia Universidad Católica de Perú. Disponible en https://www.youtube.com/watch?v=aE0C3fUb8uc

González Cueto, D. (2004). Una memoria visual para el futuro. La situación de los archivos fotográficos en el Caribe Colombiano. Memorias. Revista digital de historia y arqueología desde el caribe, 1[1], p.p. 1-14. Uninorte, Barranquilla, Colombia.

González, J. (2007). Ética y libertad. México: FCE, UNAM.

Hasselkus M., Hans. (1993). WOOH. Introducción al conocimiento de los Mayas. México: Hasselkus.

Ibarra Rosales, G. (2007, agosto). Ética y valores profesionales. Reencuentro, 49, p.p. 43-50, Universidad Autónoma Metropolitana Unidad Xochimilco Distrito Federal, México. Disponible en https://www.redalyc.org/pdf/340/34004907.pdf.

Ishikawa Lariú. A. y Strandberg, L. (2009). Negocios inclusivos: creando valor para las empresas y para la población de bajos ingresos. 5. Cátedra "la Caixa" de Responsabilidad Social de la Empresa y Gobierno Corporativo. Navarra: IESE Business School Universidad de Navarra.

Kandinsky, V. (2003): Punto, línea sobre el plano. Contribución al análisis de los elementos pictóricos. Buenos Aires: Paidós.

Kaplún, M. (1998). Una pedagogía de la comunicación. Madrid: Ediciones de la Torre.

Kettunen, H. y Helmke, Ch. (2004). Introducción a los jeroglificos mayas. Manual para el taller de escritura. (s.l): Universida de Helsinki, University College, Londres, Universidad de La Laguna.

Knórosov, Y. (1982). Maya Hierogliphic codes. (Traducido del ruso por Sopphie D. Coe). Nueva York: Institute for Mesoamerican Studies-State University of New York at Albany.

Ledesma, M. (2003). El diseño gráfico una voz pública (de la comunicación social a la era del individualismo). Argentina: Editorial Argonauta.

Lizarazo Arias, D. (2006). Panofsky en clave hermenéutica. Vínculos móviles en la interpretación de las imágenes. Versión, 17. 257-287.

López Artero, E. (2011). Memoria visual. Disponible en http://oftalmologia-avanzada. blogspot.com/2011/09/memoria-visual-que-es-la-memoria.html

Maldonado Alcudia, A. V. del C., Alvarado Borrego, A. y Contreras Loera, M. R. (2015, octubre). El papel social de las cooperativas, un estudio de caso. XX Congreso Internacional de Contaduría Administración e Informática. UNAM. FCA, ANFECA, ALAFEC. Disponible en http://congreso.investiga.fca.unam.mx/docs/xx/docs/9.03.pdf

Martínez Loera, R. V. (2011). Mayas y tseltales, una identidad tejida en la vida. Tesis doctoral recuperada de file://C:/Users/HabitatF/Downloads/Ver\%C3\%B3nica\%20 Mart\%C3\%ADnez-final.pdf 
Maurer Ávalos, E. (1984). Los Tseltales. México Centro de Estudios Educativos. A.C.

Maurer Ávalos, E. (2007). La armonía. Misión de Bachajón. Archivo electrónico. Documento electrónico proporcionado por el autor el 2 de diciembre de 2008.

Maurer Ávalos, E. (2009). Los tseltales. México Centro de Estudios Educativos. A.C.

Mejía Lozada, D. I. (2004). La artesanía de México. México: El Colegio de Michoacán.

Meza Salcedo, G. (2017). Ética de la investigación desde el pensamiento indígena: derechos colectivos y el principio de la comunalidad. Revista Bioética y Derecho, 41, p.p. 141159. Barcelona. Disponible en http://scielo.isciii.es/scielo.php?script=sci_arttext\&pid $=$ S1886-58872017000300019

Morales Aldana, L. (2006, abril). Geometría Maya. Las matemáticas en la enseñanza media, 4(38). Disponible en http://www.matematicaparatodos.com/varios/mayas02.pdf

Morante López, R. B. (2000, invierno). El universo mesoamericano. Conceptos integradores. Desacatos, 005. 95-106. Disponible en http://redalyc.uaemex.mx/src/inicio/ArtPdfRed. jsp?iCve $=13900507$

Navarro, H. (2005, junio). Manual para la evaluación de impacto de proyectos y programas de lucha contra la pobreza. Serie Manuales 41. Santiago de Chile: Instituto Latinoamericano y del Caribe de Planificación Económica y Social (ILPES). Área de Proyectos y programación de inversiones.

Olivares, E. y Vilahur, L. (2014). Dibujo para diseñadores gráficos. Barcelona: Parramón.

Panofsky, E. (1996). El significado de las artes visuales. Madrid: Alianza Editorial.

Paoli, A. (2003). Educación, Autonomía y lekil kuxlejal: aproximaciones sociolingüisticas a la sabiduría de los tseltales. México DF: UAM-X, CSH, Depto. de Educación y Comunicación.

París Pombo, M. D. (2007). Indigenismo cardenista y la renovación de la clase política chiapaneca (1936-1940). Tierra y población en el Chiapas decimonómico. Revista Pueblos y fronteras digital, 3. Disponible en http://www.pueblosyfronteras.unam.mx

Pelta, R. (2010). Diseñar hoy. Temas contemporáneos de diseño gráfico (1998-2003). Barcelona: Paidós.

Rains, D. G. (2002). Principios de Neuropsicología humana. México: Mc Graw Hill.

Russo, H. (2002). "La educación ¿sigue siendo estratégica para la sociedad?”. En Torres, Carlos Alberto (comp.) Paulo Freire y la agenda de la educación latinoamericana en el siglo XXI. Buenos Aires: CLACSO.

Soliz Kuncar, M. A. (2012). El diseñador, un operador cultural. La Paz, Bolivia: Mask.

Turok, M. (1988). Cómo acercarse a la artesanía. México: Plaza y Valdés Editores.

Turok, M. (s.f). Manual de diferenciación entre artesanía y manualidad. México: SEDESOL, FONART, PRODAR.

Urrego-Mendoza, Z.C., Coral-Palchucán, G. A., Aristizabal- Ch. C., Tobler Alejandra Bello-Urrego, T. A. y Bastidas-Jacanamijoy. L. O. (2017, noviembre-diciembre) Consideraciones éticas para la investigación en salud con pueblos indígenas de Colombia. Ensayo. Rev. salud pública 19[6]. Disponible en https://www.scielosp.org/pdf/rsap/2017. v19n6/827-832/es

Vara Miranda, M. J. (1985). La empresa cooperativa y su equilibrio económico-social. Revesco-Estudios Cooperativos, 53. Madrid. Universidad Complutense. 
Womack, J. (1998). Chiapas, el obispo de San Cristóbal y la revuelta zapatista. México. Editorial, Cal y Arena.

Abstract: In the municipality of Chilón, Chiapas is the cooperative "jLuchiyej Nichimietic", a space where the embroidery of two hundred indigenous tseltal women are sold. They have created an iconography related to the flora and fauna of the region and also to some expressions of their worldview. To preserve the visual legacy, a project was generated that documented the symbolic meaning of the drawings through creative techniques generated from the design. It is important to mention that this activity has an ethical background that challenges to preserver knowledge and does not use the material for purposes other than those of the cooperative.

Keywords: indigenous embroiderers - iconographic memory - ethical engagement - social responsibility - professional ethics.

Resumo: No município de Chilón, Chiapas é a cooperativa "jLuchiyej Nichimietic", um espaço onde é comercializado o bordado de duzentas mulheres indígenas da comunidade tseltal. Elas criaram uma iconografia relacionada à flora e fauna da região e também a algumas expressões de sua visão de mundo. Para preservar o legado visual, foi gerado um projeto que registro o significado simbólico dos desenhos através de técnicas criativas geradas a partir do design. É importante ressaltar que essa atividade tem um contexto ético que desafia a preservação de conhecimento e não use o material para fins diferentes aos da cooperativa.

Palavras chave: bordadeiras indígenas - memória iconográfica - engajamento ético - responsabilidade social - ética profissional.

[Las traducciones de los abstracts fueron supervisadas por el autor de cada artículo] 